International Journal of Environmental Research and

Article

www.mdpi.com/journal/ijerph

\title{
The Effects of Fine Particulate Air Pollution on Daily Mortality: A Case-Crossover Study in a Subtropical City, Taipei, Taiwan
}

\author{
Shang-Shyue Tsai ${ }^{1}$, Chih-Ching Chang ${ }^{2}$, Saou-Hsing Liou ${ }^{3}$ and Chun-Yuh Yang ${ }^{3,4, *}$ \\ 1 Department of Healthcare Administration, I-Shou University, Kaohsiung 824, Taiwan; \\ E-Mail: sionghak@isu.edu.tw \\ 2 Department of Environmental and Occupational Health, National Cheng Kung University, Tainan \\ 701, Taiwan; E-Mail: chang3@mail.ncku.edu.tw \\ 3 Division of Environmental Health and Occupational Medicine, National Health Research Institute, \\ Miaoli 350, Taiwan; E-Mail: shliou@nhri.org.tw \\ 4 Department of Public Health, College of Health Sciences, Kaohsiung Medical University, \\ Kaohsiung 807, Taiwan
}

* Author to whom correspondence should be addressed; E-Mail: chunyuh@kmu.edu.tw; Tel.: +886-7-312-1101 (ext. 2141); Fax: +886-7-311-0811.

Received: 12 February 2014; in revised form: 5 May 2014 / Accepted: 5 May 2014 /

Published: 12 May 2014

\begin{abstract}
This study was undertaken to determine whether there was an association between $\mathrm{PM}_{2.5}$ levels and daily mortality in Taipei, Taiwan, the largest metropolitan city with a subtropical climate. Daily mortality, air pollution, and weather data for Taipei were obtained for the period from 2006-2008. The relative risk of daily mortality was estimated using a time-stratified case-crossover approach, controlling for weather variables, day of the week, seasonality, and long-term time trends. For the single pollutant model, $\mathrm{PM}_{2.5}$ showed association with total mortality both on warm $\left(>23{ }^{\circ} \mathrm{C}\right)$ and cool days $\left(<23{ }^{\circ} \mathrm{C}\right)$. There is no indication of an association between $\mathrm{PM}_{2.5}$ and risk of death due to respiratory diseases both on warm and cool days. $\mathrm{PM}_{2.5}$ had effects on the risk of death from cardiovascular diseases only on cool days. In the two-pollutant models, $\mathrm{PM}_{2.5}$ remained effects on the risk of mortality for all cause and cardiovascular disease after the inclusion of $\mathrm{SO}_{2}$ and $\mathrm{O}_{3}$ both on warm and cool days. This study provides evidence that short-term exposure to $\mathrm{PM}_{2.5}$ increased the risk of death for all cause and cardiovascular disease.
\end{abstract}


Keywords: fine particulate; air pollution; daily mortality; case-crossover

\section{Introduction}

Over the past decade, many epidemiologic studies have demonstrated positive associations between ambient levels of airborne particulate matter (PM, generally measured as PM with an aerodynamic diameter $\left.\leq 10 \mu \mathrm{m}\left[\mathrm{PM}_{10}\right]\right)$ and daily mortality [1-7] and hospital admissions or emergency room (ER) visits for cardiovascular and respiratory morbidity [8-12]. The evidence on adverse effects of PM air pollution on public health has led to more stringent standards for levels of PM in outdoor air in the USA and in other countries [13,14].

While previous studies have primarily used $\mathrm{PM}_{10}$ as an exposure indicator, fine particles (defined as PM with an aerodynamic diameter less than $2.5 \mu \mathrm{m} ; \mathrm{PM}_{2.5}$ ) have become a greater health and regulatory concern due to epidemiologic studies suggesting that $\mathrm{PM}_{2.5}$ might exert greater toxicity than larger particles [15-18]. It is now generally accepted that $\mathrm{PM}_{2.5}$ are more harmful for health than larger particles $\left(\mathrm{PM}_{10}\right)$ because $\mathrm{PM}_{2.5}$ can be inhaled more deeply into the lungs and offer a greater surface area and hence potentially larger concentrations of adsorbed or condensed toxic air pollutants per unit mass $[19,20]$. It is for this reason that the World Health Organization (WHO) recommends using $\mathrm{PM}_{2.5}$ rather than $\mathrm{PM}_{10}$ concentrations as indicators of air quality [7].

Relatively few epidemiologic studies have been undertaken which address the association between $\mathrm{PM}_{2.5}$ and rate of mortality because only few cities have monitored $\mathrm{PM}_{2.5}$ [17,21-37]. Because these studies were conducted primarily in American and European cities [17,25,26,28,29,32,33,37], the findings may not be applicable to Asian countries such as Taiwan, where characteristics of study context may be different, such as levels of $\mathrm{PM}_{2.5}$, population sensitivity to $\mathrm{PM}_{2.5}$, variability in $\mathrm{PM}_{2.5}$ composition and toxicity [38]. In addition, the findings have been inconsistent. Thus the association between $\mathrm{PM}_{2.5}$ and mortality needs further study.

To our knowledge, only a few Taiwanese epidemiological studies have investigated the acute effects of $\mathrm{PM}_{2.5}$, which is due to the lack of suitable monitoring data [39-44]. This study was undertaken to examine the association between short-term exposure to $\mathrm{PM}_{2.5}$ and daily mortality among individuals residing in Taipei city, the largest metropolitan city in Taiwan, over a 3 year period from 2006-2008, using a case-crossover design.

\section{Materials and Methods}

\subsection{Taipei City}

This study examined daily mortality in relation to $\mathrm{PM}_{2.5}$ levels in Taipei for the 3-year period from 2006 through 2008. Taipei is the largest metropolitan city in Taiwan with a population of approximately 2.64 million located in northern Taiwan. The major air pollution source is automobile exhaust emission. Taipei has a subtropical climate, with an annual average temperature of $23{ }^{\circ} \mathrm{C}$. 


\subsection{Mortality Data}

Total daily deaths were obtained within the Taipei city from the Department of Health (DOH), which is in charge of the death registration system, for the period from 2006 through 2008 (daily mortality data from DOH were not available nationwide after the year of 2009). For each death, detailed demographic information, including gender, date of death, date of birth, cause of death, place of death, and residential district were recorded. Deaths due to accidents (ICD-9 codes 800-999) and deaths occurring outside of the city were excluded from the analysis. The deaths were divided into the following two groups according to the International Classification of Diseases, 9th revision (ICD-9): (1) diseases of the respiratory system (ICD-9 codes 460-519); and (2) diseases of cardiovascular systems (ICD-9 codes 390-459).

\subsection{PM 2.5 and Meteorological Data}

Six air quality monitoring stations were established in Taipei City by the Taiwanese Environmental Protection Administration (EPA), a central governmental agency in 1994. The monitoring stations were fully automated and routinely monitored five "criteria" pollutants including sulfur dioxide $\left(\mathrm{SO}_{2}\right.$, by ultraviolet fluorescence); particulate matter $\left(\mathrm{PM}_{10}\right.$, by $\beta$-ray absorption); nitrogen dioxide $\left(\mathrm{NO}_{2}\right.$, by ultraviolet fluorescence), carbon monoxide ( $\mathrm{CO}$, by nondispersive infrared photometry), and ozone $\left(\mathrm{O}_{3}\right.$, by ultraviolet photometry) levels. However, $\mathrm{PM}_{2.5}$ was not regularly monitored, and $\mathrm{PM}_{2.5}$ concentrations in Taiwan have only been measured continuously since 2006. $\mathrm{PM}_{2.5}$ was measured using tapered element oscillating microbalance method samplers. The availability of the monitoring network for $\mathrm{PM}_{2.5}$ provided an opportunity to investigate the impact of $\mathrm{PM}_{2.5}$ on daily mortality. For each day, hourly air pollution data were obtained for all of the monitoring stations. After calculating the hourly mean of each pollutant from the 6 stations, the 24-h average levels of these pollutants were computed. Daily information on mean temperature and mean humidity was provided by the Taipei Observatory of the Central Weather Bureau.

\subsection{Statistics}

Data were analyzed using the case-crossover technique [45-47]. This design is an alternative to Poisson time series regression models for studying the short-term effects attributed to air pollutants [48]. In general, the case-crossover design and the time-series approach yielded almost identical results [49-51].

The time-stratified approach was used for the case-crossover analysis [48]. A stratification of time into separate months was made to select referent days as the days falling on the same day of the week within the same month as the index day. Air pollution levels during the case period were compared with exposures occurring on all referent days. This time-stratified referent selection scheme minimizes bias due to non-stationarity of air pollution time-series data [52-54]. The results of previous studies indicated that increased mortality was associated with higher air pollutant levels on the same day or the previous two days [55]. Longer lag times have rarely been described. Thus the cumulative lag period up to two previous days (i.e., the average air pollutant levels of the same and previous two days) was used. Because pollutants vary considerably by season, especially $\mathrm{O}_{3}$ and particles, seasonal interactions 
between $\mathrm{PM}_{2.5}$ and daily mortality have often been reported. However, previous studies were conducted mostly in countries where the climates are substantially different from that in Taipei [56,57], which has a subtropical climate with no apparent 4-season cycle. Hence in this study the potential interactions of seasonality on the effects of $\mathrm{PM}_{2.5}$ was not considered; but temperature was used instead. The adverse health effects of each air pollutant were examined for the "warm" days (days with a mean temperature above $23{ }^{\circ} \mathrm{C}$ ) and "cool" days (days with a mean temperature below $23{ }^{\circ} \mathrm{C}$ ) separately.

The associations between mortality and levels of $\mathrm{PM}_{2.5}$ were estimated using the odds ratio (OR) and their 95\% confidence intervals (CI) which were produced using conditional logistic regression with weights equal to the number of deaths on that day. All statistical analyses were performed using the SAS package (version 9.2; SAS Institute, Inc., Cary, NC, USA). Both single-pollutant models and multi-pollutant models were fitted with a different combination of pollutants (up to two pollutants per model) to assess the stability of the effect of $\mathrm{PM}_{2.5}$. Exposure levels to air pollutants were entered into the models as continuous variables. Meteorological variables such as daily average temperature and humidity on the same day, which might play a confounding role, were included in the model. Inclusion of barometric pressure did not markedly change the effect estimates and therefore was not considered in the final model. OR were calculated for the interquartile difference (IQR, between the 25 th and the 75th percentile) for $\mathrm{PM}_{2.5}$, as observed during the study period.

\section{Results and Discussion}

Table 1 shows the demographic characteristics of the study population for all deaths, and respiratory and cardiovascular deaths. The distribution of air pollution, meteorologic measurements, and daily number of deaths in Taipei during the period from 2006 to 2008 are shown in Table 2. An average of 14 persons died of nonaccidental causes each day in the city over the study period. Median $\mathrm{PM}_{2.5}$ during study period was $27.75 \mu \mathrm{g} / \mathrm{m}^{3}$ (IQR:19.79-37.02), which is far higher than the USEPA National Ambient Air Quality Standard (NAAQS) of $15 / \mathrm{m}^{3}$ for annual $\mathrm{PM}_{2.5}$.

Table 1. Characteristics of the study population.

\begin{tabular}{ccccc}
\hline \multicolumn{2}{c}{ Characteristics } & Total Deaths & $\begin{array}{c}\text { Respiratory } \\
\text { Deaths }\end{array}$ & $\begin{array}{c}\text { Cardiovascular } \\
\text { Disease Deaths }\end{array}$ \\
\hline \multirow{2}{*}{ Gender } & Male & $9,045(57.8 \%)$ & $1,122(67.8 \%)$ & $2,539(59.0 \%)$ \\
\cline { 2 - 5 } & Female & $6,617(42.2 \%)$ & $534(32.2 \%)$ & $1,768(41.0 \%)$ \\
\hline \multicolumn{2}{c}{ Age } & $74.5 \pm 15.4$ & $80.6 \pm 12.5$ & $76.0 \pm 13.9$ \\
\hline
\end{tabular}

The Pearson's correlation coefficients among the air pollutants are presented in Table 3. There was a certain degree of correlation among the pollutants, especially between $\mathrm{PM}_{2.5}$ and $\mathrm{PM}_{10}(\mathrm{r}=0.91)$, $\mathrm{NO}_{2}$ and $\mathrm{CO}(\mathrm{r}=0.88)$, and between $\mathrm{SO}_{2}$ and both $\mathrm{PM}_{10}(\mathrm{r}=0.63)$ and $\mathrm{PM}_{2.5}(\mathrm{r}=0.61)$.

Table 4 shows the effect estimates of $\mathrm{PM}_{2.5}$ on daily mortality in single-pollutant models and two-pollutant models. For the single pollutant model (without adjustment for other pollutants), $\mathrm{PM}_{2.5}$ showed association with total mortality both on warm and cool days, with an IQR increase associated with a $7 \%(95 \% \mathrm{CI}=3 \%-11 \%)$ and $6 \%(95 \% \mathrm{CI}=3 \%-10 \%)$ rise in number of total deaths, respectively. There is no indication of an association between $\mathrm{PM}_{2.5}$ and total number of death due to 
respiratory diseases both on warm and cool days. $\mathrm{PM}_{2.5}$ had effects on the risk of death from cardiovascular diseases only on cool days (7\% increase for each IQR range change; $95 \% \mathrm{CI}=1 \%-15 \%)$.

Table 2. Mortality counts, weather, and air pollutant concentrations in Taipei, Taiwan, 2006-2008.

\begin{tabular}{|c|c|c|c|c|c|c|}
\hline Parameter $^{\mathrm{a}}$ & Min & $25 \%$ & $50 \%$ & $75 \%$ & Max & Mean \\
\hline $\mathrm{PM}_{10}\left(\mu \mathrm{g} / \mathrm{m}^{3}\right)$ & 15.33 & 36.26 & 48.01 & 62.28 & 205.35 & 52.07 \\
\hline $\mathrm{PM}_{2.5}\left(\mu \mathrm{g} / \mathrm{m}^{3}\right)$ & 8.25 & 19.79 & 27.75 & 37.02 & 117.72 & 30.65 \\
\hline $\mathrm{SO}_{2}(\mathrm{ppb})$ & 1.12 & 3.07 & 4.05 & 5.35 & 11.14 & 4.32 \\
\hline $\mathrm{NO}_{2}(\mathrm{ppb})$ & 3.73 & 20.66 & 24.53 & 29.55 & 55.51 & 25.37 \\
\hline $\mathrm{CO}(\mathrm{ppm})$ & 0.15 & 0.53 & 0.66 & 0.82 & 1.73 & 0.70 \\
\hline $\mathrm{O}_{3}(\mathrm{ppb})$ & 5.31 & 18.28 & 24.38 & 30.42 & 70.89 & 24.83 \\
\hline Temperature $\left({ }^{\circ} \mathrm{C}\right)$ & 9.35 & 19.67 & 24.32 & 28.27 & 32.78 & 23.74 \\
\hline Humidity (\%) & 47.92 & 66.95 & 73.21 & 79.28 & 94.19 & 73.02 \\
\hline Total deaths per day & 2 & 11 & 14 & 17 & 32 & 14.29 \\
\hline Respiratory deaths & 0 & 1 & 1 & 2 & 7 & 1.51 \\
\hline Cardiovascular disease death & 0 & 2 & 4 & 5 & 11 & 3.93 \\
\hline
\end{tabular}

Note: Abbreviation: Min, minimum value; Max, maximum value; ${ }^{\mathrm{a}} 24$-h average.

Table 3. Correlation coefficients among air pollutants.

\begin{tabular}{ccccccc}
\hline Variable & $\mathbf{P M}_{\mathbf{1 0}}$ & $\mathbf{P M}_{\mathbf{2 . 5}}$ & $\mathbf{S O}_{\mathbf{2}}$ & $\mathbf{N O}_{\mathbf{2}}$ & $\mathbf{C O}$ & $\mathbf{O}_{\mathbf{3}}$ \\
\hline $\mathrm{PM}_{10}$ & 1.00 & 0.91 & 0.63 & 0.47 & 0.45 & 0.40 \\
$\mathrm{PM}_{2.5}$ & - & 1.00 & 0.61 & 0.52 & 0.51 & 0.36 \\
$\mathrm{SO}_{2}$ & - & - & 1.00 & 0.49 & 0.45 & 0.13 \\
$\mathrm{NO}_{2}$ & - & - & - & 1.00 & 0.88 & -0.03 \\
$\mathrm{CO}$ & - & - & - & - & 1.00 & -0.19 \\
$\mathrm{O}_{3}$ & - & - & - & - & - & 1.00 \\
\hline
\end{tabular}

Table 4. Adjusted odds ratios (AORs) and 95\% confidence intervals (CIs) for daily mortality for each interquartile range increase of $\mathrm{PM}_{2.5}$ in Taipei, Taiwan, 2006-2008, stratified by temperature.

\begin{tabular}{cccc}
\hline & Total Deaths & Respiratory Disease & Cardiovascular Disease \\
\hline & AOR $(95 \% \mathrm{CI})^{\mathrm{a}}$ & AOR $(95 \% \mathrm{CI})^{\mathrm{a}}$ & AOR $(95 \% \mathrm{CI})^{\mathrm{a}}$ \\
\hline$\geqslant 23{ }^{\circ} \mathrm{C}(617$ days) & & & \\
Without adjustment $^{\mathrm{b}}$ & $1.07(1.03-1.11)$ & $1.08(0.96-1.21)$ & $1.07(0.99-1.15)$ \\
Adjusted for $\mathrm{SO}_{2}$ & $1.07(1.02-1.12)$ & $1.07(0.93-1.24)$ & $1.06(0.97-1.16)$ \\
Adjusted for $\mathrm{NO}_{2}$ & $1.01(0.96-1.06)$ & $1.03(0.87-1.21)$ & $1.01(0.91-1.11)$ \\
Adjusted for $\mathrm{CO}$ & $0.99(0.94-1.04)$ & $0.99(0.85-1.16)$ & $0.99(0.90-1.10)$ \\
Adjusted for $\mathrm{O}_{3}$ & $1.09(1.04-1.14)$ & $1.08(0.94-1.25)$ & $1.09(0.99-1.19)$ \\
\hline$<23{ }^{\circ} \mathrm{C}(479$ days $)$ & & & \\
Without adjustment $^{\mathrm{b}}$ & $1.06(1.03-1.10)$ & $1.04(0.92-1.17)$ & $1.07(1.01-1.15)$ \\
Adjusted for $\mathrm{SO}_{2}$ & $1.13(1.07-1.18)$ & $1.10(0.94-1.29)$ & $1.14(1.04-1.26)$ \\
Adjusted for $\mathrm{NO}_{2}$ & $0.99(0.95-1.04)$ & $0.99(0.86-1.13)$ & $1.01(0.94-1.10)$ \\
Adjusted for $\mathrm{CO}$ & $1.02(0.98-1.07)$ & $1.03(0.88-1.19)$ & $1.04(0.95-1.13)$ \\
Adjusted for $\mathrm{O}_{3}$ & $1.07(1.03-1.11)$ & $1.04(0.93-1.17)$ & $1.08(1.01-1.15)$ \\
\hline
\end{tabular}

Notes: ${ }^{\text {a }}$ Calculated for an interquartile range increases of $\mathrm{PM}_{2.5}\left(17.23 \mu \mathrm{g} / \mathrm{m}^{3}\right)$ and adjusted for temperature and humidity; ${ }^{\mathrm{b}}$ Single pollutant model. 
In two-pollutant models, $\mathrm{PM}_{2.5}$ remained effects on total mortality after the inclusion of $\mathrm{SO}_{2}$ and $\mathrm{O}_{3}$ both on warm and cool days. We observed no associations between $\mathrm{PM}_{2.5}$ and daily mortality from respiratory diseases both on warm and cool days. For daily mortality from cardiovascular diseases, the effect of $\mathrm{PM}_{2.5}$ remained when $\mathrm{SO}_{2}$ or $\mathrm{O}_{3}$ was added in the regression model on cool days.

This study is one of the few that investigated the association between exposure to $\mathrm{PM}_{2.5}$ and daily mortality in Asia. Consistent with other studies in China [24,34-36], our study found association between $\mathrm{PM}_{2.5}$ and the risk of mortality for all cause and cardiovascular disease after inclusion of $\mathrm{SO}_{2}$ or $\mathrm{O}_{3}$ in Taipei on cool days. The observed effects of $\mathrm{PM}_{2.5}$ were not maintained in the presence of $\mathrm{NO}_{2}$ or CO. It is possible that the effect of $\mathrm{PM}_{2.5}$ might have been masked by those of $\mathrm{NO}_{2}$ and $\mathrm{CO}$.

Studies conducted in US cities demonstrated significant effects of $\mathrm{PM}_{2.5}$ with increased mortality for all and specific causes [17,22,25,27,28]. Contrary to the large amount of US studies, several European studies failed to indicate significant association between $\mathrm{PM}_{2.5}$ and all cause or cause specific mortality [26,29-31,33]. However, with the exception of the study conducted in UK, these studies included relatively small populations (less than one million) [26,29,33] and/or short study periods (one year) [31]. In contrast, studies conducted in Barcelona (Spain) [23], Madrid (Spain) [32] and The Netherlands [37], significant associations between $\mathrm{PM}_{2.5}$ and daily mortality were observed.

We found a $3.48 \%$ (which corresponds to $6 \%$ increase per IQR increment) and $4.06 \%$ (which corresponds to $7 \%$ increase per IQR increment) increase of all-cause mortality and cardiovascular disease mortality per $10 \mu \mathrm{g} / \mathrm{m}^{3}$ increment in the 3 day moving average (lag 2) concentrations of $\mathrm{PM}_{2.5}$ during the cool days, respectively. The magnitude of $\mathrm{PM}_{2.5}$ effect estimates reported in our study were generally larger than those reported in the literatures. Ostro et al. found a $1.6 \%$ increase in cardiovascular mortality for an IQR increase of $14.6 \mu \mathrm{g} / \mathrm{m}^{3}$ for $\mathrm{PM}_{2.5}$ exposure [22]. Franklin et al. showed an association between $\mathrm{PM}_{2.5}$ and all-cause mortality of $1.12 \%$ and stroke mortality of $1.36 \%$ increase, per $10 \mu \mathrm{g} / \mathrm{m}^{3}$ of $\mathrm{PM}_{2.5}$ in 27 US cities [27]. Dominici et al. found a $\mathrm{PM}_{2.5}$ effect of $0.29 \%$ per $10 \mu \mathrm{g} / \mathrm{m}^{3}$ increase for all-cause mortality [25]. A multi-city analysis in 112 US cities showed that $10 \mu \mathrm{g} / \mathrm{m}^{3}$ increment of $\mathrm{PM}_{2.5}$ was associated with $1 \%$ increase of total mortality, $0.9 \%$ increase of cardiovascular mortality, and $1.7 \%$ increase of respiratory mortality [17]. The increase in all cause mortality associated with a $10 \mu \mathrm{g} / \mathrm{m}^{3}$ increase in $\mathrm{PM}_{2.5}$ ranged from $1.4 \%$ in Barcelona and $0.8 \%$ in The Netherlands [23,37]. Although study methods might have influenced the analysis results, disparities in findings between ours and Western populations provide evidence of the differential toxicity of $\mathrm{PM}_{2.5}$ with different components across locations and on various health outcomes [36]. The basis for differences in these studies is not known. One potential explanation for this discrepancy is that most published studies only demonstrated straightforward pooled effect estimates (lack of effect estimates stratified by season). This may conceal inherent differences between different climates and air pollution mixtures. Further, variations in seasonal and regional effect estimates may in part result from differences in the chemical composition of $\mathrm{PM}_{2.5}$ [38,58]. Nevertheless, the seasonal pattern of air pollution health effects needs to be further investigated.

In our study, associations between $\mathrm{PM}_{2.5}$ and the risk of death for cardiovascular diseases were observed only on cool days. The observed seasonal variation in effect estimates may be explained by variation in exposure patterns. It could be related to the subtropical climate, with very warm summers and mild winters in Taipei. The mean daily temperature rarely falls below $15{ }^{\circ} \mathrm{C}$. People in Taipei therefore are more likely to go outdoors and open the windows in the cool season than in warm season 
(higher exposure); thus, monitored $\mathrm{PM}_{2.5}$ concentrations may be closer to personal exposure to $\mathrm{PM}_{2.5}$ in the cool than warm season (interaction between air pollution and temperature and better exposure assessment). This fact may attenuate the $\mathrm{PM}_{2.5}$-induced effect in the warm season. On the other hand, seasonal differences in air pollution mixture may also affect the effect estimates.

Some pathophysiological hypotheses may be inferred to explain the mechanisms underlying $\mathrm{PM}_{2.5}$-induced damage to the cardiovascular system. $\mathrm{PM}_{2.5}$ have been postulated as the effective toxic fraction of PM, because they promote and maintain oxidative stress both at the respiratory level (the entry system) and at the systemic level where oxidative stress induces inflammatory reactions $[59,60]$. Cardiovascular effects may reflect neurogenic and inflammatory processes [61]. Mechanisms for the potential effects of $\mathrm{PM}_{2.5}$ on cardiovascular disease may include changes in blood coagulability [62], increased circulating markers of inflammation [61,63,64], and alterations in autonomic nervous system control of the heart [2,65-67]. These results suggest altered hemodynamics that may lead to an increased risk of cardiovascular events.

Air pollution has consistently been associated with increased hospital admissions and daily mortality in cities throughout the world. Recent studies suggest that the increase is due primarily to $\mathrm{PM}_{2.5}[16,68]$. Major $\mathrm{PM}_{2.5}$ components vary by region and by season, but typically include ammonium sulfate and nitrate, elemental carbon, carbonaceous species, carbonates, metals, and water [68,69]. Despite considerable research, the relative toxicity of different constituents of $\mathrm{PM}_{2.5}$ remains unclear but likely varies [68].

The origin of chemical pollutants in an urban atmosphere is known to be principally due to road traffic [70]. $\quad \mathrm{PM}_{2.5}$ concentrations possess a less important natural component than $\mathrm{PM}_{10}$ concentrations. This smaller natural component makes $\mathrm{PM}_{2.5}$ a more reliable indicator than $\mathrm{PM}_{10}$ for measuring anthropic activity in a large city [71].

The case-crossover study design was proposed by Maclure to study the influence of transient, intermittent exposures on the subsequent risk of rare acute-onset events in close temporal proximity to exposure [45]. This design offers the ability to control many confounders by design rather than by statistical modelling. This design is an adaptation of the case-control study in which each case serves as his or her own referent. Therefore time-invariant subject-specific variables such as gender, age, underlying chronic disease, or other individual-level characteristics do not act as confounders. In addition, time-stratified approach [48] was found to be effective in controlling for seasonality, time trends, and chronic and slowly varying potential confounders [37,52,54]. In general, the case-crossover design and the general additive model (GAM) approach, which has been the analytic method of choice for studying short-term adverse effects of air pollution since 1990 [72], produced almost identical results [49-51].

For a factor to confound the relationship between $\mathrm{PM}_{2.5}$ levels and daily mortality it needs to be correlated with both variables. It is unlikely that smoking and other indoor pollutants confound the present association since day to day variations in indoor emissions, including smoking may not be correlated with $\mathrm{PM}_{2.5}$ air pollution.

Our study has several limitations. First, $\mathrm{PM}_{2.5}$ levels were assigned from fixed, outdoor monitoring stations to individuals to estimate exposure (assuming that exposure was homogeneous over all the studied area). Measurement errors resulting from differences between the population average exposure and ambient $\mathrm{PM}_{2.5}$ levels are not avoidable. However, this kind of measurement error will result in 
nondifferential misclassification. However, this exposure misclassification is likely to cause a bias toward the null and lead to underestimate of pollutant effects $[55,73]$. Second, our study population is homogenous in terms of race compared with populations in other cities and this study was conducted in a subtropical city. These facts may restrict somewhat the generalizability of these findings to other locations with different meteorological and racial characteristics. Third, behavior such as air conditioning usage or time spent outdoors may affect personal exposures. This might affect the magnitude of the observed associations compared with other geographical locations. Fourth, influenza epidemics and pneumonia morbidity may also be significant determinants of respiratory mortality. We were unable to control for these two potential confounding variables due to the lack of available information.

\section{Conclusions}

In summary, this study provided evidence of associations between short-term exposure to $\mathrm{PM}_{2.5}$ and increased risk of death for all cause and cardiovascular disease. The ecological design of the study precludes the inference of cause and effect. However, these findings reinforce the possible role of $\mathrm{PM}_{2.5}$ on adverse health effects.

\section{Acknowledgments}

This study is based in part on data from the National Insurance Research Database provided by the Bureau of National Health Insurance, Department of Health and managed by National Health Research Institutes. The interpretation and conclusions contained herein do not represent those of Bureau of National Health Insurance, Department of Health or National Health Research Institutes. This study was supported by National Health Research Institutes (EO-101-PP-08) and National Science Council, Taiwan (NSC-102-2314-B-037-065-MY2).

\section{Author Contributions}

Shang-Shyue Tsai wrote the manuscript and did the statistical analysis. Chih-Ching Chang and Saou-Hsing Liou provided essential insight into the interpretation of the results. Chun-Yuh Yang contributed to study design and interpretation of the data.

\section{Conflicts of Interest}

The authors declare no conflict of interest.

\section{References}

1. Levy, J.I.; Hammitt, J.K.; Spengler, J.D. Estimating the mortality impacts of particulate matter: What can be learned from between-study variability? Environ. Health Persp. 2000, 108, 109-117.

2. Pope, C.A., 3rd.; Burnett, R.T.; Thurston, G.D.; Thun, M.J.; Calle, E.E.; Krewski, D.; Godleski, J.J. Cardiovascular mortality and long-term exposure to particulate air pollution: Epidemiological evidence of general pathophysiological pathways of disease. Circulation 2004, 109, 71-77. 
3. Goodman, P.G.; Dockery, D.W.; Clancy, L. Cause-specific mortality and the extended effects of particulate pollution and temperature exposure. Environ. Health Persp. 2004, 112, 179-185.

4. Schwartz, J. The effects of particulate air pollution on daily deaths: A multi-city case-crossover analysis. Occup. Environ. Med. 2004, 61, 956-961.

5. Analitis, A.; Katsouyanni, K.; Dimakopoulou, K.; Samoli, E.; Nikoloulopoulos, A.K.; Petasakis, Y.; Touloumi, G.; Schwartz, J.; Anderson, H.R.; Cambra, K.; et al. Short-term effects of ambient particles on cardiovascular and respiratory mortality. Epidemiology 2006, 17, 230-233.

6. Cohen, A.J.; Anderson, H.R.; Ostro, B.; Pandey, K.D.; Krzyzanowsli, M.; Kunzli, N.; Gutschmidt, K.; Pope, A.; Romieu, I.; Samet, J.M.; et al. The global burden of disease due to outdoor air pollution. J. Toxicol. Environ. Health A 2005, 68, 1301-1307.

7. WHO. WHO Air Quality Guidelines, Global Update 2005; World Health Organization: Geneva, Switzerland, 2006.

8. Samet, J.; Krewski, D. Health effects associated with exposure to ambient air pollution. J. Toxicol. Environ. Health A 2007, 70, 227-242.

9. Zanobetti, A.; Schwartz, J.; Dockery, D.W. Airborne particles are a risk factor for hospital admissions for heart and lung disease. Environ. Health Persp. 2000, 108, 1071-1077.

10. Le Tertre, A.; Medina, S.; Samoli, E.; Forsberg, B.; Michelozzi, P.; Boumghar, A.; Vonk, J.; Bellini, A.; Atkinson, R.; Ayres, J.; et al. Short-term effects of particulate air pollution on cardiovascular diseases in eight European cities. J. Epidemiol. Community Health 2002, 56, 773-779.

11. Bedeschi, E.; Campari, C.; Candela, S.; Collini, G.; Caranci, N.; Frasca, G.; Galassi, C.; Francesca, G.; Vigotti, M.A. Urban air pollution and respiratory emergency visits at pediatric unit, Reggio Emilia, Italy. J. Toxicol. Environ. Health A 2007, 70, 261-265.

12. Krewski, D.; Burnett, R.; Jerrett, M.; Pope, C.A.; Rainham, D.; Calle, E.; Thurston, G.; Thun, M. Mortality and long-term exposure to ambient air pollution: Ongoing analyses based on the American cancer society cohort. J. Toxicol. Environ. Health A 2005, 68, 1093-1109.

13. Dominici, F.; Peng, R.D.; Bell, M.L.; Pham, L.; McDermott, A.; Zeger, S.L.; Samet, J.M. Fine particulate air pollution and hospital admission for cardiovascular and respiratory diseases. J. Am. Med. Assoc. 2006, 295, 1127-1134.

14. Craig, L.; Brook, J.R.; Chiotti, Q.; Croes, B.; Gower, S.; Hedley, A.; Krewski, D.; Krupnick, A.; Krzyzanowski, M.; Moran, M.D.; et al. Air pollution and public health: A guide document for risk managers. J. Toxicol. Environ. Health A 2008, 71, 588-698.

15. Cifuentes, L.A.; Vega, J.; Kopfer, K.; Lave, L.B. Effect of the fine fraction of particulate matter versus the coarse mass and other pollutants on daily nortality in Santiago Chile. J. Air Waste Manag. Assoc. 2000, 50, 1287-1298.

16. Schwartz, J.; Dockery, D.W.; Neas, L.M. Is daily mortality associated specifically with fine particles? J. Air Waste Manag. Assoc. 1996, 46, 927-939.

17. Zanobetti, A.; Schwartz, J. The effect of fine and coarse particulate air pollution on mortality: A national analysis. Environ. Health Perspect. 2009, 117, 898-903.

18. Liao, D.; Shaffer, M.L.; He, F.; Rodriguez-Colon, S.; Eu, R.; Whitsel, E.A.; Bixler, E.O.; Cascio, W.E. Fine particulate air pollution is associated with higher vulnerability to atrial fibrillation-The APACR study. J. Toxicol. Environ. Health A 2011, 74, 693-705. 
19. Wilson, W.E.; Suh, H.H. Fine particles and coarse particles: Concentration relationship relevant to epidemiologic studies. J. Air Waste Manag. Assoc. 1997, 47, 1238-1249.

20. Pope, C.A.; Dockery, D.W. Health effects of fine particulate air pollution: Lines that connect. J. Air Waste Manag. Assoc. 2006, 36, 709-742.

21. Venners, S.A.; Wang, B.; Xu, Z.; Schlatter, Y.; Wang, L.; Xu, X. Particulate matter, sulfur dioxide, and daily mortality in Chongqing, China. Environ. Health Persp. 2003, 111, 562-567.

22. Ostro, B.; Broadwin, R.; Green, S.; Feng, W.; Lipsett, M. Fine particulate air pollution and mortality in nine California counties: Results from CALFINE. Environ. Health Persp. 2006, 114, $29-33$.

23. Ostro, B.; Tobias, A.; Querol, X.; Alastuey, A.; Amato, F.; Pey, J.; Pérez, N.; Sunyer, J. The effects of particulate matter sources on daily mortality: A case-crossover study of Barcelona, Spain. Environ. Health Perspe. 2011, 119, 1781-1787.

24. Kan, H.; London, S.J.; Chen, G.; Zhang, Y.; Song, G.; Zhao, N.; Jiang, L.; Chen, B. Differentiating the effects of fine and coarse particles on daily mortality in Shanghai, China. Environ. Int. 2007, 33, 376-384.

25. Dominici, F.; Peng, R.D.; Zeger, S.; White, R.H.; Samet, J.M. Particulate air pollution and mortality in the United States: Did the risks change from 1987 to 2000? Am. J. Epidemiol. 2007, 166, 880-888.

26. Stolzel, M.; Breitner, S.; Cyrys, J.; Pitz, M.; Woelke, G.; Kreyling, W.; Heinrich, J.; Wichmann, H.E.; Peters, A. Daily mortality and particulate matter in different size classes in Erfurt, Germany. J. Expo. Sci. Environ. Epidemiol. 2007, 17, 458-467.

27. Franklin, M.; Zeka, A.; Schwartz, P. Association between $\mathrm{PM}_{2.5}$ and all-cause and cpecific-cause mortality in 27 US communities. J. Expo. Sci. Environ. Epidemiol. 2007, 17, 279-287.

28. Franklin, M.; Koutrakis, P.; Schwartz, P. The role of particle composition on the association between $\mathrm{PM}_{2.5}$ and mortality. Epidemiology 2008, 19, 680-689.

29. Halonen, J.I.; Lanki, T.; Yli-Tuomi, T.; Tiittanen, P.; Kulmala, M.; Pekkanen, J. Particulate air pollution and acute cardiorespiratory hospital admissions and mortality among the elderly. Epidemiology 2009, 20, 143-153.

30. Atkinson, R.W.; Fuller, G.W.; Anderson, H.R.; Harrison, R.M. Urban ambient particles and health. A time series analysis. Epidemiology 2010, 21, 501-511.

31. Branis, M.; Vyskovska, J.; Maly, M.; Hovorka, J. Association of size-resolved number concentrations of particulate matter with cardiovascular and respiratory hospitals and mortality in Prague, Czech Republic. Inhal. Toxicol. 2010, 22, 21-28.

32. Mate, T.; Guaita, R.; Pichiule, M.; Linares, C.; Diaz, J. Short-term effects of fine particulate matter $\left(\mathrm{PM}_{2.5}\right)$ on daily mortality due to diseases of circulatory system in Madrid (Spain). Sci. Total Environ. 2010, 408, 5750-5757.

33. Garrett, P.; Casimiro, E. Short-term effect of fine particulate matter $\left(\mathrm{PM}_{2.5}\right)$ and ozone on daily mortality in Lisbon, Portugal. Environ. Sci. Pollut. Res. 2011, 18, 1585-1592.

34. Ma, Y.; Chen, R.; Pan, G.; Xu, X.; Song, W.; Chen, B.; Kan, H. Fine particulate air pollution and daily mortality in Shenyang, China. Sci. Total Environ. 2011, 409, 2473-2477. 
35. Yang, C.; Peng, X.; Huang, W.; Chen, R.; Xu, Z.; Chen, B.; Kan, H. A time-stratified case-crossover study of fine particulate matter air pollution and mortality in Guangzhou, China. Int. Arch. Environ. Health 2012, 85, 579-585.

36. Huang, W.; Cao, J.; Tao, Y.; Dai, L.; Lu, S.E.; Hou, B.; Wang, Z.; Zhu, T. Seasonal variation of chemical species associated with short-term mortality effects of $\mathrm{PM}_{2.5}$ in Xi'an, a central city in China. Am. J. Epidemiol. 2012, 175, 556-566.

37. Janssen, N.A.H.; Fischer, P.; Marra, M.; Ameling, C.; Cassee, F.R. Short-term effects of $\mathrm{PM}_{2.5}$, $\mathrm{PM}_{10}$, and $\mathrm{PM}_{2.5-10}$ on daily mortality in the Netherlands. Sci. Total Environ. 2013, 463, $20-26$.

38. Bell, M.L.; Ebisu, K.; Peng, R.D.; Walker, J.; Samet, J.M.; Zeger, S.L.; Dominici, F. Seasonal and regional short-term effects of fine particles on hospital admissions in 202 US counties, 1999-2005. Am. J. Epidemiol. 2008, 168, 1301-1310.

39. Hung, L.J.; Tsai, S.S.; Chen, P.S.; Yang, Y.H.; Liou, S.H.; Wu, T.N.; Yang, C.Y. Traffic air pollution and risk of death from breast cancer in Taiwan: Fine particulate matter $\left(\mathrm{PM}_{2.5}\right)$ as a proxy marker. Aerosol Air Qual. Res. 2012, 12, 275-282.

40. Hung, L.J.; Chan, T.F.; Wu, C.H.; Chiu, H.F.; Yang, C.Y. Traffic air pollution and risk of death from ovarian cancer in Taiwan: Fine particulate matter $\left(\mathrm{PM}_{2.5}\right)$ as a proxy marker. J. Toxicol. Environ. Health A 2012, 75, 174-182.

41. Hsieh, Y.L.; Tsai, S.S.; Yang, C.Y. Fine particulate air pollution and hospital admissions for congestive heart failure: A case-crossover study in Taipei. Inhal. Toxicol. 2013, 25, 455-460.

42. Chiu, H.F.; Tsai, S.S.; Weng, H.H.; Yang, C.Y. Short-term effects of fine particulate air pollution on emergency room visits for cardiac arrhythmias: A case-crossover study in Taipei. J. Toxicol. Environ. Health A 2013, 76, 614-623.

43. Chang, C.C.; Kuo, C.C.; Liou, S.H.; Yang, C.Y. Fine particulate air pollution and hospital admissions for myocardial infarction in a subtropical city: Taipei, Taiwan. J. Toxicol. Environ. Health A 2013, 76, 440-448.

44. Tsai, S.S.; Chang, C.C.; Yang, C.Y. Fine particulate air pollution and hospital admissions for chronic obstructive pulmonary disease: A case-crossover study in Taipei. Int. J. Environ. Res. Public Health 2013, 10, 6015-6026.

45. Maclure, M. The case-crossover design: A method for studying transient effects on the risk of acute events. Am. J. Epidemiol. 1991, 133, 144-153.

46. Marshall, R.J.; Jackson, R.T. Analysis of case-crossover designs. Stat. Med. 1993, 12, 2333-2341.

47. Mittleman, M.A.; Maclure, M.; Robins, J.M. Control sampling strategies for case-crossover studies: An assessment of relative efficiency. Am. J. Epidemiol. 1995, 142, 91-98.

48. Levy, D.; Lumley, T.; Sheppard, L.; Kaufman, J.; Checkoway, H. Referent selection in case-crossover analyses of acute health effects of air pollution. Epidemiology 2001, 12, 186-192.

49. Neas, L.N.; Schwartz, J.; Dockery, D. A case-crossover analysis of air pollution and mortality in Philadelphia. Environ. Health Persp. 1999, 107, 629-631.

50. Lee, J.T.; Schwartz, J. Reanalysis of the effects of air pollution on daily mortality in Seoul, Korea: A case-crossover design. Environ. Health Persp. 1999, 107, 633-636.

51. Lu, Y.; Zeger, S. On the equivalence of case-crossover and time series methods in environmental epidemiology. Biostatistics 2007, 8, 337-344. 
52. Lumley, T.; Levy, D. Bias in the case-crossover design: Implications for studies of air pollution. Environmetrics 2000, 11, 689-704.

53. Janes, H.; Sheppard, L.; Lumley, T. Case-crossover analyses of air pollution exposure data: Referent selection strategies and their implications for bias. Epidemiology 2005, 16, 717-726.

54. Mittleman, M.A. Optimal referent selection strategies in case-crossover studies: A settled issue. Epidemiology 2005, 16, 15-16.

55. Katsouyanni, K.; Touloumi, G.; Spix, C.; Schwartz, J.; Balducci, F.; Medina, S.; Rossi, G.; Wojtyniak, B.; Sunyer, J.; Bacharova, L.; et al. Short-term effects of ambient sulphur dioxide and particulate matter on mortality in 12 European cities: Results from time series data from the APHEA project. Br. Med. J. 1997, 314, 1658-1663.

56. Chang, C.C.; Tsai, S.S.; Ho, S.C.; Yang, C.Y. Air pollution and hospital admissions for cardiovascular disease in Taipei, Taiwan. Environ. Res. 2005, 98, 114-119.

57. Yang, C.Y.; Chang, C.C.; Chuang, H.Y.; Tsai, S.S.; Wu, T.N.; Ho, C.K. Relationship between air pollution and daily mortality in a subtropical city: Taipei, Taiwan. Environ. Int. 2004, 30, 519-523.

58. Zeka, A.; Zanobetti, A.; Schwartz, J. Individual-level modifiers of the effects of particulate matter on daily mortality. Am. J. Epidemiol. 2006, 163, 849-859.

59. MacNee, W.; Donaldson, K. Mechanisms of lung injury caused by $\mathrm{PM}_{10}$ and ultrafine particles with special references to COPD. Eur. Respir. J. 2003, 21 (Suppl. 40), 47s-51s.

60. Ghio, A.J.; Carraway, M.S.; Madden, M.C. Composition of air pollution particles and oxidative stress in cells, tissues, and living systems. J. Toxicol. Environ. Health B 2012, 15, 1-21.

61. Brook, R.D.; Franklin, B.; Cascio, W.; Hong, Y.; Howard, G.; Lipsett, M.; Luepker, R.; Mittleman, M.; Samet, J.; Smith, S.C., Jr.; et al. Air pollution and cardiovascular disease. A statement for healthcare professionals from the Expert Panel on Population and Prevention Science of the American Heart Association. Circulation 2004, 109, 2655-2671.

62. Seaton, A.; MacNee, W.; Donaldson, K.; Godden, D. Particulate air pollution and acute health effects. Lancet 1995, 345, 176-178.

63. Kodavanti, U.P.; Schladweiler, M.C.; Ledbetter, A.D. Temporal association between pulmonary and systemic effects of particulate matter in healthy and cardiovascular compromised rats. J. Toxicol. Environ. Health A 2002, 65, 1545-1569.

64. Ulrich, M.M.W.; Alink, G.M.; Kumarathasan, P.; Vincent, R.; Boere, A.J.F.; Cassee, F.R. Health effects and time course of particulate matter on the cardiopulmonary system in rats with lung inflammation. J. Toxicol. Environ. Health A 2002, 65, 1571-1595.

65. Liao, D.; Creason, J.; Shy, C.; Williams, R.; Watts, R.; Zweidinger, R. Daily variation of particulate air pollution and poor cardiac autonomic control in the elderly. Environ. Health Persp. 1999, 107, 521-525.

66. Gold, D.R.; Litonjua, A.; Schwartz, J.; Lovett, E.; Larson, A.; Nearing, B.; Allen, G.; Verrier, M.; Cherry, R.; Verrier, R. Ambient pollution and heart rate variability. Circulation 2000, 101, 1267-1273.

67. Devlin, R.B.; Ghio, A.J.; Kehrl, H.; Sanders, G.; Cascio, W. Elderly humans exposed to concentrated air pollution particles have decreased heart rate variability. Eur. Respir. J. 2003, 21 (Suppl. 40), $76-80$. 
68. Suh, H.H.; Zanobetti, A.; Schwartz, J.; Coull, B.A. Chemical properties of air pollutants and cause-specific hospital admissions among the elderly in Atlanta, Georgia. Environ. Health Persp. 2011, 119, 1421-1428.

69. Peng, R.D.; Bell, M.L.; Geyh, A.S.; McDermott, A.; Zeger, S.L.; Samet, J.M.; Dominici, F. Emergency admissions for cardiovascular and respiratory diseases and the chemical composition of fine particle air pollution. Environ. Health Perspect. 2009, 117, 957-963.

70. Linares, C.; Diaz, J. Short-term effect of concentrations of fine particulate matter on hospital admissions due to cardiovascular and respiratory causes among the over-75 age group in Madrid, Spain. Public Health 2010, 124, 28-36.

71. Linares, C.; Diaz, J. Short-term effect of $\mathrm{PM}_{2.5}$ on daily hospital admissions in Madrid (2003-2005). Int. J. Environ. Health Res. 2010, 20, 129-140.

72. Schwartz, J.; Marcus, A. Mortality and air pollution in London: A time series analysis. Am. J. Epidemiol. 1990, 131, 185-194.

73. Zeger, S.L.; Thomas, D.; Dominici, F.; Samet, J.M.; Schwartz, J.; Dockery, D.; Cohen, A. Exposure measurement error in time-series studies of air pollution: Concepts and consequences. Environ. Health Perspect. 2000, 108, 419-426.

(C) 2014 by the authors; licensee MDPI, Basel, Switzerland. This article is an open access article distributed under the terms and conditions of the Creative Commons Attribution license (http://creativecommons.org/licenses/by/3.0/). 